SPECIAL REPORT

\title{
CARDIAC REHABILITATION UPTAKE FOLLOWING MYOCARDIAL INFARCTION, PERCUTANEOUS CORONARY INTERVENTION AND CARDIAC SURGERY: A LOCAL SCENARIO
}

\begin{abstract}
\section{BACKGROUND}

The suboptimal utilization of Cardiac Rehabilitation (CR) poses a challenge to health policy makers in the prevention and management of coronary heart diseases. Therefore, there is an increased need to understand the factors affecting CR attendance, to reduce the wide gap between the proven benefits of $C R$ and its clinically low utilization.
\end{abstract}

\section{OBJECTIVE}

To determine attendance rate and factors affecting outpatient CR enrollment

\section{METHODS}

Total 2267 patients were included where the eligibility criterion was set according to broadened candidacy for CR programs. Patients with severe functional impairment or any co-existing debilitating morbidities in which exercise was contraindicated were excluded. RESULTS

The mean age of patients was $57.43 \pm 12.2$ years and $75.7 \%$ were males. Out of 221 (10\%) enrolled patients, 188 patients $(83.2 \%)$ completed $>6$ weeks of outpatient CR and $49.6 \%$ patients had undergone CABG surgery. Significant association was found between CR attendance and patient's medical diagnosis \& procedure $(P<0.01)$, ethnicity $(P<0.05)$ and educational level $(P<0.01)$. No association was found between $C R$ attendance and patient's gender, age and employment status. Among non-attendees, $58.6 \%$ had undergone $\mathrm{PCl}$ and $16.2 \%$ had no formal education.

\section{CONCLUSION}

Patients who were educated and underwent CABG surgery had better attendance. Considerable efforts need to be taken to use patient-specific CR to reduce ethnic and cultural barriers.

\section{KEYWORDS}

Attendance Rate, Cardiac Rehabilitation, Myocardial Infarction, Percutaneous Coronary Intervention, Cardiac Surgery, Ethnicity
Farzana Amir Hashmi

Deputy General Manager, HOD

Preventive Cardiology and Cardiac Rehabilitation Tabba Heart Institute farzana.hashmi@tabbaheart.org

\section{Marium Sheikh}

Sr. Therapeutic Dietitian Preventive Cardiology and Cardiac Rehabilitation Tabba Heart Institute mariam.sheikh@tabbaheart.org

[Hashmi FA, Sheikh M. Cardiac Rehabilitation uptake following Myocardial Infarction, Percutaneous Coronary Intervention and Cardiac Surgery: A Local Scenario. Pak. j. rehabil. 2016;5(2):19-24] 


\section{INTRODUCTION}

On a global scale, cardiovascular diseases (CVD) cause 17.3 million deaths annually, a number that is expected to grow to more than 23.6 million by 2030 . Each year, it is estimated that 785,000 Americans suffer from myocardial infarction (MI). The risk of recurrent $\mathrm{Ml}$ or a fatal event within five years is about $15 \%$ in men and $22 \%$ in women lage $45-64$ years) and $22 \%$ in both men and women (age $\geq 65$ years)'. Therefore, it is of utmost importance to prevent this high risk secondary cardiac event among CVD patients².

Cardiac rehabilitation (CR) as defined by World Health Organization (WHO) is the sum of activity required to provide cardiac patients the best avenue that aid in presuming their optimal functions within the society through improvements in their health behaviors and by delaying or opposing their ailment progression ${ }^{3}$.

CR is not only subjected to the improvements in the functional capacity and the psychosocial quality of life of patients, but it poses tremendous benefits in decreasing the morbidity and mortality among them ${ }^{4-6}$ Recent data have proven a dose response relationship between comprehensive, structured CR programs and reduction in mortality and recurrent $\mathrm{Ml}$ risk among patients with percutaneous coronary intervention $(\mathrm{PCI})^{7}$, patients with stable angina and those who underwent coronary artery bypass grafting (CABG) surgery ${ }^{8}$.

Although there is compelling research evidence regarding the diverse benefits of multifaceted $C R$ programs, worldwide the attendance rate is dismally low. Even in developed nations like in United States (US), only $10 \%$ to $20 \%$ of greater than 2 million potential cardiac candidates attend $\mathrm{CR}^{6}$.

The huge gap between the significantly proven treatment benefits of cardiac rehabilitation and the underutilization among populations is unacceptable. There are various identified social, medical and demographic determinants that act as barriers of optimal CR referral and attendance in the developed nations. These include older age, gender, lack of physician referral, perceived unsuitability, and lack of knowledge about CR benefits, low self-efficacy, lack or limited support from the family, low socio-economic status (SES), poor job timings and co-morbidities 9.10 . In our region, limited data exist that shed light on the possible barriers of optimal participation at $\mathrm{CR}$ programs. The data suggest patient unwillingness, unavailability of CR programs; low SES and lack of health insurance are the most common limitations ${ }^{11}$. The American Heart Association (AHA) focused on the immense need of appropriate patient referral for cardiac rehabilitation and understanding of their social and medical profiles to get maximum utilization and retention of $C R$ programs $^{3}$. CR is now considered as an essential element of the standard cardiac treatment ${ }^{12}$. CR is not just a traditional physical therapy program, but it is a multifaceted approach to provide optimal benefits on physical and psychosocial functions of cardiac patients. The components of CR are structured to slow or reverse disease progression, promotion of healthy lifestyle and stress regulation ${ }^{13}$. In recent years considering the proven efficacy of $C R$ programs, the eligibility criterion for enrollment in comprehensive CR sessions has been broadened. Now the scope includes all forms of CVD, patients who underwent PCl or CABG surgery, heart transplantation and stable congestive heart failure (CHF) patients and those with peripheral artery disease (PAD) with claudication'.

Benefits of cardiac rehabilitation are well documented in the present literature. Various studies have proven the efficacy of these programs in terms of reductions in morbidity and mortality. Results of a meta-analysis showed significant reductions in cardiac related mortality and all-cause mortality among patients who attended $\mathrm{CR}^{14}$. In another meta-analysis, significant association was found between exercise-based CR and reductions in the recurrent events of $\mathrm{Ml}$, cardiac and all-cause mortality ${ }^{15}$. Moreover, recent meta-analysis presented the benefits of CR in $17 \%$ reduction in recurrent $\mathrm{Ml}$ event at 12 months and $47 \%$ reduction in mortality at 24 months $^{16}$. The American Heart Association (AHA) and the American College of Cardiology Foundation (ACCF) refer CR as Class I-level recommendation for the prevention and management of coronary heart disease (CHD) ${ }^{17}$. It is surprising that instead of proven benefits of CR, the enrollment status is relatively very poor. Among potential candidates, $14 \%-35 \%$ of Ml survivors and $31 \%$ of patients' undergone CABG surgery attend $C^{18,19}$. There are several identified patient and system related factors associated with poor attendance at $C^{20}$. Lack of physician referral, poor system for reinforcement, co-morbidities, personal unsuitability, lack of motivation, female gender, low SES, long distance from residence, transportation, limited family and social support, low level of education, and low self-efficacy are some of the consistent factors found to be associated with poor enrollment at CR in developed nation ${ }^{21}$. This sub-optimal utilization of CR continues to inflict challenges to health policy makers working for prevention and management of coronary artery diseases (CAD). Sufficient data related to factors affecting attendance rates in local settings are not present. Therefore, there is an increased need to understand these factors in our local scenario in order to reduce wide intervention gap between the proven benefits of $C R$ and its clinically low utilization. The aim of the present study was to determine attendance rate and the factors affecting outpatient cardiac rehabilitation enrollment. 


\section{METHODS}

A cross-sectional study was conducted at Tabba Heart Institute (THI) to investigate factors affecting CR enrollment after cardiac procedures specifically myocardial infarction, percutaneous coronary intervention and cardiac surgery. THI is a specialty cardiac care hospital located in a populous area in Karachi that caters patients from different socioeconomic backgrounds. Moreover, this state-ofthe-art cardiac hospital is the only set up in the city that offers supervised cardiac rehabilitation program. The Preventive Cardiology and Cardiac Rehabilitation Department at THI provides tailored CR program including monitored and supervised exercises, patient and family education and individual diet consultation. CR team designed by keeping in view a multi-disciplinary approach which included dietitian, trained CR Physiotherapists, cardiac nurses, diabetes educator and other allied health professionals, working in close coordination with cardiologists/cardiac surgeons. Purposive sampling method was used and 2267 eligible patients admitted from July 2014 to April 2015 were enrolled. The eligibility criterion was set according to the broadened candidacy for CR programs. Detailed information about the structure of CR was given to all eligible patients before discharge and the potential candidates were referred for $C R$ within 2-3 days after percutaneous coronary intervention (PCI) procedure and 5-6 days after cardiac surgery, while in other countries $C R$ is offered after few weeks from discharge. Clinical and socio-demographic information were obtained.

The data analysis was performed using SPSS (Statistical Package for Social Sciences), Version 16. Age was computed as mean \pm SD. Percentages and frequencies were calculated for continuous variables. To test association between CR enrollment status and patients' characteristics, chi-square test was used.

\section{RESULTS}

The mean age ( \pm SD) of patients was 57.43 ( \pm 12.2) years and $75.7 \%$ were males. Out of 2267 patients, only 221 patients (10\%) enrolled and attended CR and among 221 attendees, 188 patients (83.2\%) completed more than 6 weeks of outpatient hospital-based CR program. Significant association was found between CR attendance and patient medical diagnosis and procedure $(P<0.01)$, ethnicity $(P<0.05)$ and educational level $(P<0.01)$.

Conversely, no association was found between CR attendance and patient gender, age and employment status. Among non-attendees, $58.6 \%$ had undergone percutaneous coronary intervention (PCl) and $16.2 \%$ had no formal education about
CR. Moreover, $49.6 \%$ patients who attended CR had undergone cardiac surgery.

\section{DISCUSSION}

The study conducted with the aim of determining factors affecting outpatient cardiac rehabilitation enrollment and attendance revealed numerous factors that can be addressed in order to improve CR attendance rate. Our study reported enrollment rate of $10 \%$ of the referred group of patients which strongly supports findings from previous studies that concluded that CR services are underutilized ${ }^{19,22,23}$

The present studies presented no association between CR attendance and patient gender and age which seconds results found in a study done in our local scenario"l. Although the enrollment percentage of patients older than 49 years of age was greater as compared to their younger counter parts but the difference was not significant enough to draw a conclusion.

Patient medical diagnosis and procedure $(P<0.01)$ was found to be a significant determinant of $C R$ enrollment which adds strength to the conclusions drawn in previous research 19,24,25. Patients gone through CABG surgery had the maximum rate of participation (49.6\%) while those gone through $\mathrm{PCl}$ were in the highest percentage among non-attendees (58.6\%). In accordance to a previous study, significant association was found between $C R$ attendance and ethnicity $(P<0.05)$ and educational level $(P<0.01)^{26}$. Our study has highlighted underutilization and major barriers related to $C R$ among patient's undergone cardiac procedures in a local scenario. These findings can further be used to overcome barriers faced by patients.

\section{CONCLUSION}

Although CR information was provided to all eligible patients before discharge, only a fraction availed CR services. Low level of education might contribute to impaired apprehension about CR benefits. Patients who underwent $\mathrm{PCl}$ are more likely to consider their medical condition as less severe and return to their jobs early as they do not find any limitation in performing routine tasks. Therefore, education about the efficacy of CR on clinical stability, improved health and subsequently superior quality of life should be provided

\section{ACKNOWLEDGEMENT}

The authors would like to thank Tabba Heart Institute, Karachi for permitting to conduct this study in their setting including patients who gave of their time to this study. 


\begin{tabular}{|c|c|c|c|}
\hline CHARACTERISTICS & $\begin{array}{c}\text { Non-enrolled Group } \\
(n=2401) \\
\%(n)\end{array}$ & $\begin{array}{c}\text { Enrolled Group } \\
(n=226) \\
\%(n)\end{array}$ & P-value \\
\hline \multicolumn{4}{|l|}{ GENDER } \\
\hline Male & $75.5(1541)$ & $77.9(176)$ & \multirow{2}{*}{0.43} \\
\hline Female & $24.5(500)$ & $22.1(50)$ & \\
\hline \multicolumn{4}{|l|}{ Ethnicity } \\
\hline Urdu Speaking & $49.3(1007)$ & $50.4(114)$ & \multirow{8}{*}{$<0.05$} \\
\hline Sindhi & $19.6(401)$ & $15(34)$ & \\
\hline Balochi & $1.6(33)$ & $0.9(2)$ & \\
\hline Punjabi & $15(306)$ & $15.5(35)$ & \\
\hline Pathan & $5.1(104)$ & $4.9(11)$ & \\
\hline Memon & $6.7(136)$ & $9.7(22)$ & \\
\hline Hindu & ---- & & \\
\hline Others* & $2.6(54)$ & $3.5(8)$ & \\
\hline \multicolumn{4}{|l|}{ Age Group } \\
\hline 49 years or less & $23.7(483)$ & $19.5(44)$ & \multirow{4}{*}{0.291} \\
\hline $50-59$ years & $31.6(645)$ & $36.3(82)$ & \\
\hline $60-69$ years & $27.9(570)$ & $31.9(72)$ & \\
\hline 70 years or above & $16.8(343)$ & $12.4(28)$ & \\
\hline \multicolumn{4}{|l|}{ Education } \\
\hline No Formal Education & $16.2(330)$ & $10.6(24)$ & \multirow{7}{*}{$<0.01$} \\
\hline Primary & $5.2(106)$ & $4(9)$ & \\
\hline Secondary & $10.2(208)$ & $8.4(19)$ & \\
\hline Matriculation & $20.1(411)$ & $18.6(42)$ & \\
\hline Intermediate & $21.2(432)$ & $24.8(56)$ & \\
\hline Graduation & $26.6(12)$ & $32.3(73)$ & \\
\hline Post-Graduation & $0.6(12)$ & $1.3(3)$ & \\
\hline \multicolumn{4}{|l|}{ Employment } \\
\hline On job & 47.7 (973) & $50.4(114)$ & \multirow{3}{*}{0.32} \\
\hline Retired & $27.2(555)$ & $27.4(62)$ & \\
\hline Without job & $25.1(513)$ & $22.1(50)$ & \\
\hline \multicolumn{4}{|c|}{ Admitting Diagnosis and Procedures } \\
\hline VHD & $1.5(30)$ & $3.1(7)$ & \multirow{7}{*}{$<0.01$} \\
\hline Open Heart Surgery & $1.4(29)$ & $2.2(5)$ & \\
\hline $\mathrm{PCl}$ & $58.6(1196)$ & $35.8(81)$ & \\
\hline CABG & $21.8(444)$ & $49.6(112)$ & \\
\hline $\mathrm{CCF}$ & $13.1(268)$ & $6.6(15)$ & \\
\hline LV Dyfunction & $3.4(69)$ & $1.8(4)$ & \\
\hline Any other & $0.2(5)$ & $0.9(2)$ & \\
\hline
\end{tabular}




\section{REFERENCES}

[1] Mozaffarian D, Benjamin EJ, Go AS, Arnett DK, Blaha MJ, Cushman M, et al. Heart disease and stroke statistics-2015 update: A report from the American Heart Association. Circulation. 2015;131 (4):e29-39

[2] Roger VL, Go AS, Lloyd-Jones DM, Adams RJ, Berry JD, Brown TM, et al. Heart disease and stroke statistics-2011 update: A report from the American Heart Association. Circulation. $2011 ; 123(4): e 18-e 209$

[3] Murphy E, Ardehali H, Balaban RS, Dilisa F, li GWD, Kitsis RN, et al. AHA Scientific Statement. 2016:118(12):1960-1991

[4] Taylor RS, Brown A, Ebrahim S, Jolliffe J, Noorani H, Rees K, Skidmore B, Stone JA, Thompson DR, Oldridge N. Exercise-based rehabilitation for patients with coronary heart disease: systematic review and meta-analysis of randomized controlled trials. Am J Med. 2004; 1 16(10):682-692

[5] Higgins HC, Hayes RL, McKenna KT. Rehabilitation outcomes following percutaneous coronary interventions (PCI). Patient Educ Couns. 2001;43(3):219- 230

[6] Leon AS, Franklin BA, Costa F, Balady GJ, Berra KA, Stewart KJ, et al. Cardiac Rehabilitation and Secondary Prevention of Coronary Heart Disease: an American Heart Association Scientific Statement From the Council on Clinical Cardiology (Subcommittee on Exercise, Cardiac Rehabilitation, and Prevention) and the Council on Nutrition, Physical Activity, and Metabolism (Subcommittee on Physical Activity), in collaboration with the American association of Cardiovascular and Pulmonary Rehabilitation. Circulation. 2005; 111 (3):369-376

[7] Goel K, Lennon RJ, Tilbury RT, Squires RW, Thomas RJ. Impact of cardiac rehabilitation on mortality and cardiovascular events after percutaneous coronary intervention in the community. Circulation. 2011;123(21):2344-2352

[8] Hammill BG, Curtis LH, Schulman KA, Whellan DJ. Relationship between cardiac rehabilitation and long-term risks of death and myocardial infarction among elderly medicare beneficiaries. Circulation. 2010;121 (1):63-70

[9] French DP, Cooper A, Weinman J. Illness perceptions predict attendance at cardiac rehabilitation following acute myocardial infarction: A systematic review with meta-analysis. J Psychosom Res. 2006;61 (6):757-767

[10] Yohannes AM, Yalfani A, Doherty P, Bundy C. Predictors of drop-out from an outpatient cardiac rehabilitation programme. Clin Rehabil. 2007;21 (3):222-229

[1 1] Ali M, Qadir F, Javed S, Khan ZN, Asad S, Hanif B. Factors affecting outpatient cardiac rehabilitation attendance after acute myocardial infarction and coronary revascularization - a local experience. J Pak Med Assoc. 2012;62(4):347-351

[12] Mampuya WM. Cardiac rehabilitation past, present and future: an overview. Cardiovasc Diagn Ther. 2012;2(1):38-49

[13] Balady GJ, Williams MA, Ades PA, Bittner V Comoss P, Foody JM, et al. Core components of cardiac rehabilitation/secondary prevention programs: 2007 update - A scientific statement from the American Heart Association exercise, cardiac rehabilitation, and prevention commitee, the council on clinical cardiology; the councils on cardiovascular nursing, epidemiology and prevention, and nutrition, physical activity, and metabolism; and the American Association of Cardiovascular and Pulmonary Rehabilitation. Circulation. 2007;1 15(20):2675-2682

[14] O'Connor GT, Buring JE, Yusuf S, et al. An Overview of Randomized Trials of Rehabilitation With Exercise After Myocardial Infarction. Circulation. 1989;80(2)234-245

[15] Lawler PR, Filion KB, Eisenberg MJ. Efficacy of exercise-based cardiac rehabilitation post-myocardial infarction: a systematic review and meta-analysis of randomized controlled trials. Am Hear J. 201 1;162(4):571-584

[16] Clark AM, Hartling L, Vandermeer B, McAlister FA. Meta-analysis: secondary prevention programs for patients with coronary artery disease. Ann Intern Med. 2005; 143(9):659-672

[17] Perk J, De Backer G, Gohlke H, Graham I, Reiner $Z$, Verschuren $M$, et al. European Guidelines on cardiovascular disease prevention in clinical practice (version 2012). Eur Heart J. 2012;33(13):1635-701

[18] Centers for Disease Control and Prevention (CDC). Receipt of outpatient cardiac rehabilitation among heart attack survivors--United States, 2005. MMWR Morb Mortal Wkly Rep. 2008;57(4):89-94

[19] Suaya JA, Shepard DS, Normand SL, Ades PA, Prottas J, Stason WB. Use of cardiac rehabilitation by Medicare beneficiaries after myocardial infarction or coronary bypass surgery. Circulation. 2007;1 16(15):1653-1662

[20] Balady GJ, Ades PA, Bittner VA, Franklin BA, Gordon NF, Thomas RJ, et al. Referral, enrollment, and delivery of cardiac rehabilitation/secondary prevention programs at clinical centers and beyond: A presidential advisory from the american heart association. Circulation. 201 1;124(25):2951-2960

[21] Daly J, Sindone AP, Thompson DR, Hancock K, Chang $E$, Davidson P. Barriers to participation in and adherence to cardiac rehabilitation programs: a critical literature review. Prog Cardiovasc Nurs. 2002;17(1):8-17

[22] Scott IA, Lindsay KA, Harden HE. Utilisation of outpatient cardiac rehabilitation in Queensland. Med J Aust. 2003;179(7):341-345

[23] Martin BJ, Haver T, Arena R, Austford LD, 
Galbraith PD, Lewin AM, et al. Cardiac rehabilitation attendance and outcomes in coronary artery disease patients. Circulation. $2012 ; 126(6): 677-687$

[24] Jackson L, Leclerc J, Erskine Y, Linden W. Getting the most out of cardiac rehabilitation: a review of referral and adherence predictors. Heart. 2005;91(1):10-4
[25] Suaya JA, Stason WB, Ades PA, Normand SL, Shepard DS. Cardiac Rehabilitation and Survival in Older Coronary Patients. J Am Coll Cardiol. 2009:54(1):25-33

[26] Allen JK, Scott LB, Stewart KJ, Young DR. Disparities in women's referral to and enrollment in outpatient cardiac rehabilitation. J Gen Intern Med. 2004;19(7):747-753 